\title{
Images from the Haematologica Atlas of Hematologic Cytology: bone marrow metastases from gastric adenocarcinoma
}

\section{Rosangela Invernizzi}

University of Pavia, Pavia, Italy

E-mail: ROSANGELA INVERNIZZI - rosangela.invernizzi@unipv.it

doi:10.3324/haematol.2020.275529

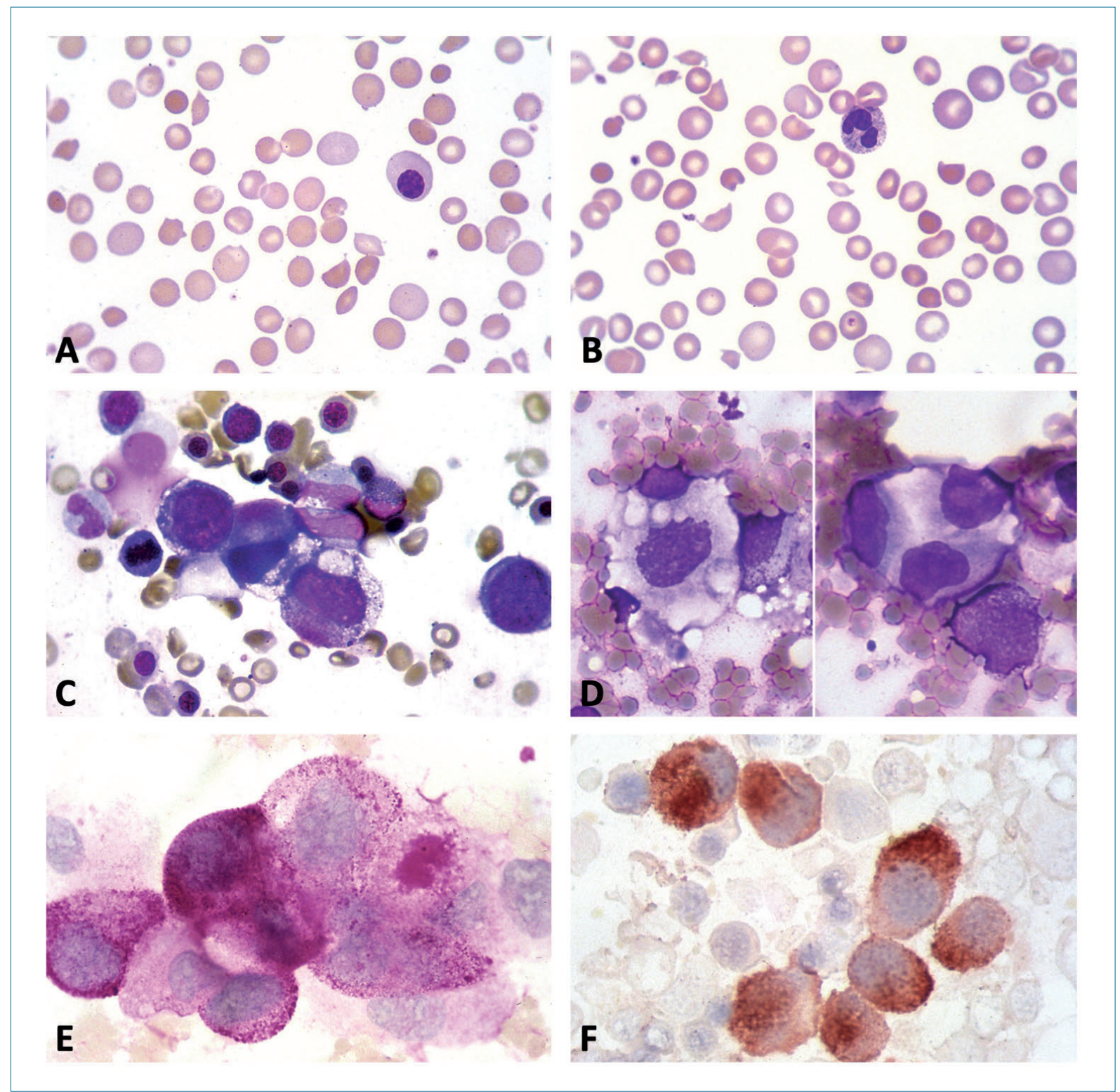

I

n some patients with disseminated gastric adenocarcinoma, microangiopathic hemolytic anemia is the presenting feature of the tumor. In this case of gastric adenocarcinoma with bone marrow metastases, an erythroblast, polychromatic red cells, microspherocytes and red cell fragmentation are observed in the peripheral blood smear (panels A and B). Bone marrow smear reveals a group of large tumor cells with irregular nuclear shape, and polychromatic, inhomogeneous, foamy or vacuolated cytoplasm (panels C and D). Periodic acid-Schiff (PAS) stain shows intense granular or diffuse cytoplasmic positivity suggesting the accumulation of polysaccharides in the neoplastic cells (panel E). The strong immunocytochemical expression of cytokeratins (immunoperoxidase technique), in association with the absence of the common leukocyte antigen, confirms the non-hematopoietic origin of tumor cells (panel F). ${ }^{1}$

\section{References}

1. Invernizzi R. Metastases of solid tumors. Haematologica. 2020; 105(Suppl 1):261-269. 